\title{
Dispositivos móveis e a formação para a cidadania digital: o desafio de família e escola
}

\author{
Flávia Cardoso Carneiro', Simão Pedro P. Marinho \\ ${ }^{1}$ Grupo Ânima - Av. Professor Mário Werneck, 1685 - Buritis - 30.575-180 - Belo \\ Horizonte - MG - Brasil \\ ${ }^{2}$ Programa de Pós-Graduação em Educação - Pontifícia Universidade Católica de \\ Minas Gerais (PUC Minas) - Avenida Itaú, 505 - Dom Cabral - 30.535-012 - Belo \\ Horizonte - MG - Brasil \\ flaviacar@yahoo.com, marinhosepucminas.br
}

\begin{abstract}
This meta-paper analyses the importance of an ethical approach to the use of new technologies in and outside school premises. The constant access to the world wide web by children and youngsters, mainly through mobile devices, sends an alert about the urgency in preparing tis public to use internet for the best purposes, avoiding risk to oneself and others. The development of digital citizenship, through programs developed by schools, families and government, has become an issue of huge importance in a super connected and complex society. It is the role of all involved in education to address this question in an articulated and responsible manner.
\end{abstract}

Resumo. Este meta-artigo aborda a importância de uma formação ética para a utilização das novas tecnologias dentro do ambiente escolar e fora dele. $O$ acesso constante à rede mundial de computadores, principalmente através dos dispositivos móveis, manda um alerta sobre a urgência na preparação deste público para o melhor uso da internet, evitando riscos para si e outros. A construção da cidadania digital, através de programas desenvolvidos por escolas e governos, com o apoio das famílias, torna-se uma questão urgente em uma sociedade que se mostra cada vez mais conectada e mais complexa. É papel de todos envolvidos em educação abordar esta questão de maneira articulada e responsável.

\section{Introdução}

Desde o final do século XX o mundo vem assistindo uma revolução apenas comparável - em abrangência e profundidade de mudanças na sociedade - à Revolução Industrial do século precedente. $\mathrm{O}$ advento da Internet, desde a sua popularização nos Estados Unidos, por volta de 1990, e no resto do mundo, em meados de 1995, vem forjando, definitiva e velozmente, uma nova sociedade. Novos hábitos, novos padrões de consumo, novas formas de trabalho vão sendo forjados na sociedade em rede, sociedade da informação, sociedade do conhecimento, sociedade digital, qual seja a expressão que se adote.

Não apenas os conceitos de modos de comunicação foram modificados, mas também os de tempo, espaço e velocidade. Um novo mundo de possibilidades abriu-se, rapidamente, diante dos olhos abismados das gerações que antecederam estas mudanças, dos adultos nascidos nas gerações anteriores, vindos de uma cultura analógica, onde os limites de tempo e espaço apresentavam-se definitivamente mais restritos. 
Indivíduos nascidos já no século XXI assimilaram os novos conceitos que se desenhavam com a naturalidade esperada de quem é exposto, desde a infância, a uma ferramenta específica, em um novo cenário. É uma geração que se forma, construída em um mundo significativamente diferente daquele de seus pais ou avós. Essa nova geração, nascida dentro dos conceitos pós-modernos de sociedade, vem se moldando na sobreposição de dois mundos paralelos: o físico e o virtual. No entanto, o conceito de uma vida online (FLORIDI, 2015) que se entrelaça à vida "real" vem se tornando uma prática habitual para toda a população humana, tenha ela testemunhado a mudança ou já nascido dentro dela. A demarcação rígida entre o online e off-line, estabelecida nos primórdios da internet, se esvai.

Temos, então, adultos, crianças e adolescentes com acesso irrestrito à informação, independentemente de sua localização no globo, ávidos por conexões rápidas e descomplicadas, assim como permitem a internet e a mobilidade do acesso, possibilitada pela invenção dos dispositivos móveis, especialmente dos smartphones.

\section{Sociedade e internet}

Cada dia mais a tecnologia ganha espaço em todos os setores da sociedade. Se tornou habitual que cada indivíduo carregue consigo pelo menos um aparelho de conexão à internet e cada vez mais crianças se comportam dessa maneira pois (MAEROFF, 2003) computadores, telefones celulares, fax e outros artefatos da última tecnologia fizeram parte de seu ambiente desde a mais tenra infância. A tecnologia da informação e os dispositivos eletrônicos são tão naturais para eles como comer e dormir.

Essa exposição das crianças, jovens e adultos à internet, mesmo que o acesso irrestrito à rede ainda não seja um fato consumado e garantido para muitas populações do planeta, apresenta possibilidades infinitas de interação e aprendizagem, da mesma forma que implica em situações e ameaças novas, inexistentes no modelo antigo de sociedade. Não queremos aqui afirmar que tais ameaças se tornaram reais e possíveis somente devido às novas ferramentas como celulares e tablets, mas que seu alcance e abrangência foram multiplicados exponencialmente por elas. No novo tempo, novas formas de antigas ameaças se realizam, certamente amplificadas pelo poder da internet.

O índice de indivíduos conectados à internet vem aumentando em ritmo constante e acelerado na maior parte dos países do mundo. No Brasil, segundo pesquisa realizada pelo Instituto Brasileiro de Geografia e Estatística (IBGE), a Pesquisa Nacional por Amostra de Domicílios Contínua (PNAD C), ao final de 2016 eram 116 milhões de brasileiros conectados à internet, o equivalente a $64,7 \%$ da população nacional com idade acima de 10 anos. Em 2015 eram 102,1 milhões, ou 57,5\% da população. A proporção de mulheres conectadas foi maior que a de homens: $65,5 \%$ delas tinham acesso á internet, enquanto, o índice para os homens era de $63,8 \%$. Considerando a faixa etária, os indivíduos com idade entre 18 e 24 anos apresentavam a maior taxa de conexão, $85 \%$ deles estavam online. Já os brasileiros com mais de 60 anos apresentavam o menor índice, de $25 \%$.

As regiões Nordeste e Norte eram as únicas a apresentar taxas de indivíduos conectados inferiores à média brasileira, de 52,3\% e 54,3\%, respectivamente. O Sudeste possuía o maior índice. Lá, 72,3\% dos moradores tinham acesso, enquanto no CentroOeste a taxa é de $71,8 \%$ e no Sul, é de $67,9 \%$. 
VII Congresso Brasileiro de Informática na Educação (CBIE 2018)

Anais dos Workshops do VII Congresso Brasileiro de Informática na Educação (WCBIE 2018)

A referida pesquisa trouxe um dado bastante importante quando abordamos os canais pelos quais se dá o acesso à internet. O celular é o principal aparelho para esse fim. Em 2016, esse dispositivo era usado por $94,6 \%$ dos internautas, à frente de computadores $(63,7 \%)$, tablets $(16,4 \%)$ e televisões $(11,3 \%)$. Segundo o IBGE, naquele anos $77,1 \%$ dos brasileiros possuíam algum aparelho celular.

A mobilidade e praticidade do acesso através de um dispositivo móvel de fácil transporte contribuiu para a ascensão do aparelho na preferência de acesso dos brasileiros. A PNAD Contínua também levantou as finalidades com que os brasileiros navegam na internet ou usam serviços conectados. A principal dessas atividades, apontada por $94,6 \%$ dos internautas, é trocar mensagens (de texto, voz ou imagens) através de aplicativos de bate-papo. Assistir vídeos (programas, séries e filmes) foi apontado por $76,4 \%$ dos brasileiros conectados e superou as conversas por chamadas de voz ou vídeo, indicadas por $73,3 \%$.

Ainda que $64,7 \%$ da população brasileira tenham declarado acessar a internet, há 63,3 milhões de pessoas que se mantêm off-line. Os principais motivos alegados para isto são o preço elevado do serviço de internet no Brasil e o desconhecimento ou o desinteresse pela utilização dos dispositivos eletrônicos.

O número de linhas telefônicas de aparelhos celulares, no entanto, dá sinais de contínuo crescimento. De acordo com a Agência Nacional de Telecomunicações (ANATEL) existem hoje, 220 milhões de celulares inteligentes, os smartphones, em funcionamento no país para uma população de 207,6 milhões de habitantes, conforme dados mais recentes do IBGE. Na prática é que como se cada brasileiro tivesse mais de um smartphone.

No entanto, compreende-se que o tempo relativamente curto em que as novas tecnologias vêm sendo usadas no mundo, não permitiu ainda que fossem tomadas medidas eficazes no uso e segurança da internet e que fossem criadas normas de conduta universais de modo a orientar e proteger seus usuários sobre a melhor maneira de utilizar as novas e poderosas ferramentas sem que isso causasse danos a si e a terceiros.

A internet, em si, como nova ferramenta, vem se apresentando como um território completamente novo e inexplorado, onde ainda não há regras e leis que regulamentem seu uso e as interações humanas que se dão através dela. Algumas iniciativas isoladas de governos mundiais vêm sendo tomadas de modo a regulamentar o comércio através da internet, por exemplo, mas uma lei digital, substancial e de largo alcance e conhecimento da população e juristas, ainda carece de aperfeiçoamento e divulgação.

Cyberbullying, aplicativos de incitação ao suicídio, roubo de dados através de computadores e celulares, exposição íntima na internet e cyberstalking são apenas algumas das novas modalidades de agressão possíveis e para as quais os usuários da internet não estão preparados, simplesmente pelo fato de que, em momento algum existiu tal preparação. Reconhece-se o fato de que existe uma nova ferramenta, de largo alcance, mas não há, de maneira geral, por parte das instituições sociais e governamentais, uma orientação formal, parâmetros definidos e difundidos entre a população, que regulamentem seu uso. Ainda que marcos regulatórios venham sendo definidos, muitos aspectos ainda estão fora do campo das orientações ou recomendações. Entre fascinados e desinformados, usuários expõem-se a todo tipo de situação em um ambiente desconhecido, cometendo e sofrendo agressões causadas pelo desconhecimento e despreparo generalizados. Alimenta-se assim, uma ideologia do ego, do poder e da 
VII Congresso Brasileiro de Informática na Educação (CBIE 2018)

Anais dos Workshops do VII Congresso Brasileiro de Informática na Educação (WCBIE 2018)

violência, que corre solta sem as limitações da lei e protegida pelo anonimato. A intimidação e a coerção de indivíduos por grupos organizados que vem crescendo nos ambientes virtuais, ilustra o fenômeno de forma clara. Nas palavras de Arendt (1994):

“A forma extrema de poder é o de todos contra um, a forma extrema da violência é um contra todos." (ARENDT, 1994, p. 35).

Nos anos 1920, John Dewey, considerado o maior filósofo americano vivo à época, abordou a questão de como a escola poderia exercer um papel de transformador social. No final da mencionada década, Dewey e um grupo de pesquisadores visitaram a Rússia para conhecer o que definiram como "o experimento de planejamento social e ação coletiva mais importante do mundo". Como o país passava por mudanças extremas nas searas política e econômica, a escola foi um fator crucial de condução dessas mudanças em um saldo positivo para a humanidade. O que impressionou os pesquisadores foi (RAVITCH, 2000) que educadores estavam conduzindo a criação de uma nova ordem social cooperativa.

Mais uma vez, famílias, escolas e governos encontram-se de frente a um desafio que deve ser abordado em conjunto, de modo a construir novas gerações de usuários que sejam cidadãos digitais, ou seja, cidadãos responsáveis e preparados para atuar e colher os benefícios de uma sociedade baseada na aplicação responsável da tecnologia, cientes de seus direitos ao mesmo tempo que conscientes de seus deveres no ciberespaço.

\section{A cidadania digital}

\footnotetext{
"Quando negamos aos estudantes oportunidades de considerar caminhos para a mudança, estamos também traindo um importante princípio da governança democrática: a necessidade de formar cidadãos capazes de sustentar debates críticos e fazer escolhas coletivas.” (WESTHEIMER, 2015, p. 45).
}

Os nove elementos da cidadania digital, elaborados pelos educadores Mike Ribble e Gerald Bailey, surgiram como uma espécie de guia, uma base para que as escolas, terminantemente inseridas na nova era da comunicação, pudessem trabalhar na criação de uma sociedade digital responsável e saudável. Seu livro, Digital Citizenship in Schools, lançado em 2007, oferecia, quando de seu lançamento, um passo a passo para escolas que desejassem criar uma consciência de responsabilidade digital em seus alunos. A mudança em curso não podia circunscrever-se a desenvolver alunos capazes de operar computadores conectados à internet para facilitar a pesquisa e diversificar as aulas, mas de construir uma sociedade mais responsável através das mesmas ferramentas.

\footnotetext{
"Considerar apenas o impacto da tecnologia no processo social das salas de aula seria como enxergar apenas metade de uma imagem. Tem ficado extremamente evidente que comportamentos e estruturas sociais preexistentes modelam a abrangência e o modo como a tecnologia será utilizada pelos indivíduos." (SCHOFIELD, 1995, p. 94).
}

As escolas estadunidenses passaram, então, a ter em mãos e através do currículo, diretrizes necessárias para contribuir na formação dessa nova sociedade atuando de maneira eficaz no desenvolvimento dos nove elementos da cidadania digital que 
VII Congresso Brasileiro de Informática na Educação (CBIE 2018)

Anais dos Workshops do VII Congresso Brasileiro de Informática na Educação (WCBIE 2018)

compreendem: acesso digital, comércio digital, comunicação digital, letramento digital, etiqueta digital, lei digital, direitos e responsabilidades digitais, saúde e bem-estar digitais e segurança digital. Obviamente que as escolas sozinhas não lograrão alcançar seus objetivos caso estas ações não sejam coordenadas com as famílias dos estudantes, em uma parceria de apoio mútuo e identificação de obstáculos. Assim, seria mister que as duas instituições trabalhassem simultaneamente os seguintes tópicos:

\subsection{Acesso digital: participação eletrônica irrestrita na sociedade}

Precisamos considerar que nem todas as pessoas no mundo têm as mesmas oportunidades quando consideramos o uso das tecnologias digitais. $O$ ponto crucial para $\mathrm{O}$ estabelecimento da cidadania digital é o desenvolvimento de direitos iguais no que concerne o acesso e a atuação das pessoas no mundo eletrônico. A não-inclusão digital dificulta o crescimento de sociedades que estão cada dia mais (inter)ligadas pelo uso da tecnologia. O foco de governos mundo afora deveria girar em torno da promoção da expansão do acesso à tecnologia para que alcançasse todos os seus cidadãos. Considerando-se o fato que nem todos têm acesso ao uso de tecnologia, seja acesso a aparelhos ou a redes, outros meios de acesso deveriam ser pensados para solucionar o problema. Uma sociedade produtiva requer acesso digital a todas as pessoas que compõem sua população.

\subsection{Comércio digital: compra e venda de bens e serviços por meio eletrônico}

Atualmente, uma grande parcela das negociações de compra e venda de bens e serviços é feita por meio eletrônico. O comércio legal e legítimo vem ocorrendo cada dia em maior grau e frequência, mas compradores e vendedores hão de estar cientes de todas as implicações inerentes a este tipo de atividade. A disponibilidade geral da compra de brinquedos, vestuário, automóveis, alimentos e outros itens através da Internet tornou-se comum para muitos usuários de computadores, celulares e tablets. Entretanto, os usuários precisam estar alertas para o fato de que, com o crescimento do consumo legal de bens e serviços, ocorre, por sua vez, o comércio de bens e serviços ilegais ou imorais de acordo com as leis específicas de cada país, tais como download ilegal de obras literárias e fonográficas, por exemplo, bem como pornografia e jogos de azar. Os usuários de precisam aprender a como ser consumidores responsáveis na nova economia digital.

\subsection{Comunicação Digital: troca eletrônica de informações}

Uma das mudanças mais significativas dentro da revolução digital que vivenciamos consiste na forma pela qual pessoa comunica-se com outras. Até o século XIX, os modos pelos quais as pessoas se comunicavam eram extremamente limitados se comparados à explosão dos meios de comunicação no atual século. E-mail, telefones celulares, mensagens instantâneas, escaneamento de documentos, registro e envio de fotos de maneira instantânea vieram forjar uma nova concepção da palavra comunicação, de alguma forma a aldeia global se torna maisa viável. As opções trazidas pela comunicação digital mudaram a maneira pela qual as pessoas se comunicam e os tempos envolvidos nessas comunicações, permitindo a elas estar em contato de maneira constante e rápida. Agora, qualquer pessoa munida de um dispositivo digital, um celular como o recurso mais frequente, e conectada a uma rede pode colaborar e comunicar-se com qualquer oura pessoa, nas mesmas condições, a qualquer hora e em qualquer lugar do mundo. 
VII Congresso Brasileiro de Informática na Educação (CBIE 2018)

Anais dos Workshops do VII Congresso Brasileiro de Informática na Educação (WCBIE 2018)

Infelizmente, muitos usuários não tiveram a chance de ser informados sobre como fazer boas escolhas diante de tantas opções de comunicação.

\subsection{Letramento Digital: processo de ensinar e aprender sobre tecnologia e seu uso}

Enquanto as escolas têm feito grandes progressos na área da tecnologia de informação, muito está ainda por fazer. Há uma necessidade premente por um novo foco acerca de quais tecnologias a serem ensinadas e como deveriam ser usadas. Novas tecnologias estão invadindo os espaços de trabalho, sendo usadas diariamente, e ao mesmo tempo, não estão sendo ensinadas na escola. Na seara do mundo do trabalho ocorre também que funcionários em várias diferentes ocupações, precisam de informações imediatas, (justin-time information). Este processo requer habilidades sofisticadas de busca $\mathrm{e}$ processamento de informações (letramento informacional). Aprendizes precisam ser preparados para como aprender numa sociedade digital. Em outras palavras aprendizes precisam ser ensinados a como aprender qualquer coisa, a qualquer hora, em qualquer lugar. O mundo dos negócios, as forças armadas e a medicina são excelentes exemplos de como a tecnologia vem sendo usada diferentemente no século XXI. À medida que novas tecnologias surgem, as pessoas precisam aprender como usá-las de maneira rápida e apropriada. A ideia da cidadania digital envolve também o fato de que as pessoas precisam ser educadas de uma maneira nova, pois a elas é requerido um alto nível de competência em letramento informacional. Da mesma maneira que ocorreu durante a Revolução Industrial, onde novas concepções de tempo, espaço e novas maneiras de vida, invadiram os lares e espaços de trabalho das pessoas, usuários das tecnologias digitais precisam reaprender com as novas possibilidades.

\subsection{Etiqueta digital: padrões eletrônicos de conduta e procedimentos}

Os usuários de tecnologia usualmente vêm essa área como um dos problemas mais prementes no que concerne à Cidadania Digital. Os seres humanos reconhecem um comportamento não apropriado quando o vêm, mas antes de usar a tecnologia, as pessoas não aprendem sobre as condutas mais apropriadas na internet. Muitas pessoas sentem-se desconfortáveis em falar com outras sobre sua etiqueta digital. Na maioria dos casos, regras e regulamentos são criados para conter os abusos ou a tecnologia é simplesmente banida do ambiente como meio de parar o uso considerado como inapropriado, como acontece em tantas escolas. A criação de regras e políticas de uso não chega a ser suficiente, faz-se necessário educar as pessoas no intuito de fazê-las participar nessa nova sociedade como cidadãos digitais responsáveis.

\subsection{Lei Digital: responsabilidade eletrônica sobre obras e ações}

A lei digital trata da ética da tecnologia dentro de uma sociedade. O uso antiético manifesta-se através do roubo ou crime digital. $\mathrm{O}$ uso ético, ao contrário, manifesta-se através do comportamento consoante com as regras da sociedade. Os usuários precisam entender que o furto ou danos a qualquer trabalho, identidade ou propriedade de outra pessoa online é considerado crime. Existem certas regras dentro de uma sociedade das quais os usuários devem estar a par dentro de uma sociedade ética e que essas regras são aplicáveis a qualquer pessoa que trabalhe ou se divirta online. Aceder ilegalmente a informações de outrem, fazer download ilegal de músicas e filmes, plagiar, criar worms, vírus ou Cavalos de Tróia, mandar spam ou roubar a identidade ou propriedade de qualquer pessoa é considerado antiético. 
VII Congresso Brasileiro de Informática na Educação (CBIE 2018)

Anais dos Workshops do VII Congresso Brasileiro de Informática na Educação (WCBIE 2018)

\subsection{Direitos e Responsabilidades Digitais: direitos e liberdades digitais estendidas a todas as pessoas incluídas em um mundo digital}

Como na constituição estadunidense, onde consta uma Carta de Direitos, existe uma lista de direitos básicos que deve se estender a todo e qualquer indivíduo inserido em uma sociedade digital. Cidadãos digitais têm direitos, como o da privacidade, o da liberdade de opinião. Os direitos digitais básicos devem ser abordados, discutidos e compreendidos no mundo digital. Claramente, os direitos vêm acompanhados dos deveres digitais que todos os usuários devem ter em consideração quando atuando online. O uso apropriado da internet e o respeito aos direitos de terceiros deve ser uma construção de todos de modo que este uso se torne produtivo.

\subsection{Saúde e Bem-Estar Digital: bem-estar físico e psicológico num mundo de tecnologia digital}

A segurança da visão, lesões por esforço repetitivo e boas práticas ergonômicas são questões que precisam ser abordadas num novo mundo tecnológico. Para além dos problemas físicos, estão aqueles problemas psicológicos que estão tornando-se mais prevalentes, tais como a dependência da Internet. Os utilizadores precisam ser ensinados que há perigos inerentes à tecnologia. A Cidadania Digital inclui uma cultura onde os utilizadores são ensinados a proteger-se a si próprios através da educação e da formação.

\subsection{Segurança Digital (autoproteção): precauções eletrônicas para garantir a segurança}

Tratamos aqui da necessidade de proteção contra vírus, cópias de segurança dos dados pessoais e mecanismos de controle de surtos nos equipamentos. Como cidadãos responsáveis, é necessária a adoção de processos de proteção de nossa informação contra a interferência de forças exteriores que podem causar perturbações ou danos irreversíveis como o roubo de senhas e documentos.

\section{A pesquisa: metodologia e resultados}

Foi realizada uma pesquisa com pais e responsáveis de trinta e sete alunos de escolas privadas e públicas da cidade de Belo Horizonte, Juiz de Fora e Rio de Janeiro. A pesquisa consistiu na resposta a um questionário de dez perguntas sobre preocupações dos pais quanto ao acesso ininterrupto de seus filhos à internet possibilitado pelos dispositivos móveis. Este questionário foi veiculado através da ferramenta SurveyMonkey e teve como premissa o total anonimato devido à natureza do assunto abordado, visando à proteção e liberdade dos respondentes.

A partir das respostas obtidas foi promovida uma análise com base na estatística descritiva para a identificação das preocupações da família acerca do tema tratado.

A análise dos dados coletados aponta que a maioria dos respondentes informa que os filhos têm acesso à internet pela rede wi-fi de casa e pelo celular. Segundo pesquisa do CETIC, em 2017 93\% das crianças e adolescentes brasileiros, entre 9 e 17 anos, acessavam a internet por meio do celular. (CETIC, 2018b).

Pouco mais da metade $(58,33 \%)$ dos entrevistados se preocupa com o conteúdo acessado pelos filhos. A mesma pesquisa do CETIC revelou que menos da metade (49\%) das crianças e adolescentes brasileiros, entre 9 e 17 anos, tem uma percepção de que seus 
VII Congresso Brasileiro de Informática na Educação (CBIE 2018)

Anais dos Workshops do VII Congresso Brasileiro de Informática na Educação (WCBIE 2018)

pais ou responsáveis têm muito conhecimento de suas atividades na internet; para $8 \%$ deles, o desconhecimento seria total. (CETIC, 2018b).

Daqueles que entrevistamos, 16,67\%, apesar de se preocuparem com o conteúdo, acham difícil controlar o que os filhos acessam, sendo que a abordagem dos filhos por pedófilos, figura como a principal preocupação (75\%), seguida igualmente de exposição à pornografia e contato com pessoas que possam incitar a práticas nocivas à saúde física e mental de crianças e jovens, $(66,67 \%)$. O bullying, seja aquele praticado, seja aquele sofrido, figura igualmente como uma preocupação de $30,56 \%$ dos pais ou responsáveis.

Quando o questionário aborda a segurança na web, a maioria dos pais afirma que busca proteger os filhos através de conversas explicando os perigos $(30,56 \%)$ ou através de checagem contínua dos conteúdos abordados quando os filhos estão na internet $(41,67 \%)$. A articulação com a escola sobre maneiras de proteger as crianças teve representação mínima $2,78 \%$, assim como o hábito de vasculhar escondido os aparelhos dos filhos.

Para os pais, a responsabilidade da educação dos filhos acerca das melhores práticas na Web é da própria família, segundo $61,11 \%$ dos respondentes. Um pouco mais de 52,78\% acredita que é uma tarefa que deva ser compartilhada pela escola e família. Uma parte pequena $(5,56 \%)$ entende que a responsabilidade cabe apenas à escola, por ser o lugar onde os estudantes passam mais tempo. Uma fração de $2,78 \%$ acredita que a tarefa deva ser compartilhada, porém reconhecendo uma prevalência da responsabilidade para a escola. Parece-nos importante registrar que uma pesquisa do CETIC revelou que $40 \%$ dos professores de escolas localizadas em áreas urbanas já ajudaram algum de seus alunos aluno no enfrentamento de situações desconfortáveis ocorridas durante o uso da Internet, tais como o bullying, a discriminação e o assédio (CETIC, 2018a).

Dos pais ou responsáveis, $22,86 \%$ acreditam que o comportamento de seus filhos na rede mundial de computadores é igual ao seu comportamento nas relações físicas; para $34,29 \%$ o comportamento dos filhos deve ser monitorado para evitar perigos a eles e a outros e somente $2,86 \%$ acreditam não ter influência direta no comportamento dos filhos quando esses estão online, pois cada ser humano é único independente da educação que receba. Nenhum dos entrevistados levou em consideração a afirmação de que o comportamento dos filhos possa ser pautado pela volatilidade das relações da era atual.

A maioria dos pais $(62,86 \%)$ permite que os filhos estudem consultando dispositivos móveis como celular/tablets, quase metade $(45,71 \%)$ permite que seus filhos tenham perfis em redes sociais e $42,86 \%$ que seus filhos estejam sempre com seus celulares. Apenas um respondente afirmou que permite aos filhos usarem o celular à mesa, durante as refeições, enquanto $17,14 \%$ o permitem se for uma consulta urgente ou rápida. Dos respondentes, $22,86 \%$ autorizam que seus filhos façam compras pela internet.

A maioria dos pais $(70,59 \%)$ usa sistemas antivírus como proteção de seus equipamentos digitais. Apenas $8,82 \%$ previnem problemas usando filtros de monitoramento para detectar sites não idôneos. Metade dos pais tem permissão dos filhos para acessar seus equipamentos (celular, computado ou tablet), mas somente 22,86\% têm as senhas de acesso aos dispositivos móveis dos filhos.

Os dados mostram que pais ainda têm uma noção enevoada sobre as dimensões da influência da internet sobre seus filhos. É fácil notar que acreditam ter o controle sobre o tempo, os sites e os tipos de interação de seus filhos dentro da internet. Como poucos 
VII Congresso Brasileiro de Informática na Educação (CBIE 2018)

Anais dos Workshops do VII Congresso Brasileiro de Informática na Educação (WCBIE 2018)

têm as senhas de seus filhos, torna-se inviável um monitoramento eficaz e real dos aparelhos das crianças e jovens, visto que, este monitoramento ocorre quando os indivíduos estão online apenas na presença dos pais. $\mathrm{O}$ dado mais surpreendente foi a ausência de filtros de controle nos equipamentos acessados pelos filhos, mesmo quando os pais acreditam que a responsabilidade para esta formação seja majoritariamente da família. Não há uma conscientização dos pais sobre a articulação família-escola, apesar de muitos pais acreditarem que esta função deveria ser compartilhada.

\section{Conclusão}

Apresenta-se na sociedade do novo século, uma nova, importante e decisiva missão, para as famílias e para a escola. Esta missão determinará as bases de convívio, saúde física e mental e respeito nas relações humanas inseridas em uma realidade totalmente nova onde não há comparação possível com épocas precedentes na humanidade. Os elementos que estão moldando as novas formas de relação e interação humana demandam da escola e da sociedade civil, especialmente das famílias, uma maior atenção na formação das crianças e jovens.

A globalização e o acesso à internet, principalmente através dos dispositivos móveis como tablets, notebooks e, mais especialmente, os smartphones, em sendo um movimento sem retorno, torna premente a adoção de medidas educativas, esclarecedoras e reguladoras de todas as interações humanas no mundo virtual.

O acesso, praticamente irrestrito e contínuo à internet, por crianças e jovens, possibilitada pela praticidade desses dispositivos móveis, provoca também uma urgência em se precaver o uso indiscriminado e potencialmente vil da rede. Crianças e jovens podem, a qualquer ponto, tornar-se vítimas de uma ferramenta espetacular, por falta de orientação, monitoramento e um programa de educação quanto ao uso e exploração da internet.

A abordagem direcionada e responsável sobre todos os fatores que envolvem a criação de um novo panorama de interação dos indivíduos dentro do ambiente virtual, é urgente em todos as comunidades do planeta. Sem as ações de abordagem educacional e políticas públicas de acesso e orientação sobre condutas, direitos e deveres, teremos problemas de magnitude muito maior para serem solucionados, dentro de algumas décadas.

A formação de uma nova sociedade, com novas ferramentas, possibilidades e ausência dos limites, que até então cerceavam a interação física e temporal da humanidade, é responsabilidade de todos, escolas, famílias e governos bem como de cada indivíduo dentro de seu âmbito de atuação e consciência. Para tal, precisamos educar e informar estes indivíduos para que a interação máquina/ser humano, não seja, mais uma vez, somente uma ameaça, mas sim uma fonte inesgotável de desenvolvimento e progresso. Para que todos possam viver de maneira útil e saudável no ciberespaço, a formação para a cidadania digital será uma exigência. Resta preparar pais e professores para realizar essa tarefa.

\section{Referências}

Arendt, H. (1994), “Sobre a Violência”, Editora Vozes. 
VII Congresso Brasileiro de Informática na Educação (CBIE 2018)

Anais dos Workshops do VII Congresso Brasileiro de Informática na Educação (WCBIE 2018)

CETIC (2018a), "Pesquisa TIC Educação 2017”, https://cetic.br/pesquisa/educacao/indicadores, Setembro.

CETIC (2018b), “Pesquisa TIC Kids Online Brasil 2017”, https://cetic.br/pesquisa/kidsonline/indicadores, Setembro.

Floridi, L. (Ed.) (2015), “The Onlife Manifesto: Being Human in a Hyperconnected Era", Editora Springer.

Gomes, H. S. (2018), "Brasil tem 116 milhões de pessoas conectadas à internet, diz IBGE", https://g1.globo.com/economia/tecnologia/noticia/brasil-tem-116-milhoesde-pessoas-conectadas-a-internet-diz-ibge.ghtml, Setembro.

Maeroff, G. I. (2008), “A Classroom of One: How Online Learning Is Changing Our Schools and Colleges", Editora Teachers College Press, 2. ed.

Ravitch, D. (2007), "Left Back: A Century of Battles Over School Reform”, Editora Teachers College Press.

Ribble, M., Bailey, G. (2007), "Digital Citizenship in Schools”, Editora International Society for Technology in Education.

Schofield, J. (2003), "Computers and Classroom Culture”, Editora International Society for Technology in Education.

Westheimer, J. (2015), "What Kind of Citizen? Educating our children for the common good", Editora Teachers College Press.

O grupo de pesquisa Tecnologias Digitais e Educação, do Diretório do CNPq, vinculado ao Programa de Pós-graduação em Educação da PUC Minas, tem o apoio da FAPEMIG. 